\title{
Water properties in pâtés enriched with potato juice
}

\author{
Hanna Maria Baranowska ${ }^{1}$. Lukasz Masewicz ${ }^{1}$ Przemysław Lukasz Kowalczewski ${ }^{2}$. \\ Grażyna Lewandowicz ${ }^{3} \cdot$ Michał Piątek $^{4} \cdot$ Piotr Kubiak $^{3}$
}

Received: 19 February 2017 / Revised: 14 July 2017 / Accepted: 3 August 2017 / Published online: 14 August 2017

(C) The Author(s) 2017. This article is an open access publication

\begin{abstract}
Freshly squeezed potato juice was used in the traditional European folk medicine. Potato juice can be introduced into food products both in its fresh as well as in thermally preserved form as a component of functional food. An attempt was made to analyse the impact of potato juice supplementation on qualitative and quantitative parameters characterising water bonds in poultry meat batters and pâtés. On the basis of temperature studies of water activity changes and spin-lattice and spin-spin relaxation times, the authors determined energy values of water transport in meat batters. It was found that supplementation with fresh potato juice limited significantly water transport. The performed analyses of temperature value changes of $T_{2}$ spin-spin relaxation times revealed significant differences in the molecular dynamics of both water fractions in temperatures exceeding $50{ }^{\circ} \mathrm{C}$. Measurement results of relaxation times in pâtés demonstrated that the amount of free water in relation to the amount of bound water in the examined systems depended on the addition of the probiotic factor and on the form in which it was added.
\end{abstract}

Hanna Maria Baranowska

hmbar@up.poznan.pl

1 Department of Physics and Biophysics, Poznan University of Life Sciences, Wojska Polskiego Str. 38/42, 60-637 Poznań, Poland

2 Institute of Food Technology of Plant Origin, Poznań University of Life Sciences, Wojska Polskiego Str. 31, 60-624 Poznań, Poland

3 Department of Biotechnology and Food Microbiology, Poznań University of Life Sciences, Wojska Polskiego Str. 48, 60-627 Poznań, Poland

4 Institute of Meat Technology, Poznań University of Life Sciences, Wojska Polskiego Str. 31, 60-624 Poznań, Poland
Keywords Functional food - Low-field NMR · Potato juice $\cdot$ Water activity $\cdot$ Water dynamics

\section{Introduction}

Potato juice was used in the traditional European folk medicine to alleviate gastric ulcer symptoms. Its properties and nutritional safety have started to attract scientific interest between late 20th and early 21 st century. The effectiveness of fresh potato juice was studied even in clinical trials $[1,2]$. Proteins contained in the juice are considered the main factor behind its nutritional and functional value. Their amino acid composition resembles egg protein [3], and the 4-25 kDa protein fraction of the juice has proven to inhibit proteases $[4,5]$.

The biological activity of the low-molecular fraction of potato juice is less understood. While the toxicity of glycoalkaloids, mainly solanine and chaconine, which constitute $95 \%$ of total glycoalkaloids in potato tubers, is common knowledge [6], some of the other non-protein constituents of potato juice are important for healthy nutrition. These include vitamins of group B (niacin, thiamine, riboflavin, and vitamin B6), macro- and microelements, and antioxidants (vitamins $\mathrm{C}, \mathrm{E}$ and $\beta$-carotene) [7]. Moreover, the data already available reveal some interesting therapeutic potential of the low-molecular potato juice fraction. Its cytotoxic and genotoxic activity towards intestinal cancer cells has been demonstrated by Olejnik et al. [8]. It has shown antiinflammatory activity in the gastro-intestinal tract retained even after thermal treatment [9] [10]. The mechanism behind this activity has yet to be explained. However, as it was speculated, it may be related to the antioxidant or specific antimicrobial activity $[11,12]$. 
Potato juice shows therapeutic potential. Still, it possesses negative sensory properties which make direct ingestion unpleasant. If it was to be used as an ingredient for production of functional food, the impact of this disadvantage could easily be minimized. The market for functional products has lately been observed to expand at a constant rate. The expansion was driven by increasing consumer awareness of the relation between nutrition and health. Products enriched with pro- and pre-biotics, as well as omega- 3 fatty acids, are the most popular types of functional food [13, 14]. The dynamics of IBD occurrence indicate that the market for functional products targeted at people suffering from this disease will grow rapidly. To successfully introduce such products, careful design, considering both the functional and sensory qualities, is necessary.

Potato juice may be used to enrich food both in its fresh or thermally stabilized form. The fact that such enrichment alternates the physicochemical and sensory properties of the base product must be taken into account [15-17]. As previously determined, the form in which potato juice is applied has influence on product quality [18-21]. The change in water activity value with the change of temperature is the result of the delivery the energy to the system. Water molecules have greater freedom of evacuation from the investigated material. Using the Arrhenius-type dependence, the activation energy of the process is determined. This is the process of releasing water from the product surface. The end result of this process is measured water activity.

Changes in water dynamics are of specific importance, and these can be traced using low-field nuclear magnetic resonance (NMR). Spin-lattice $T_{1}$ and spin-spin $T_{2}$ relaxation times are the parameters directly measured with this technique. The spin-lattice relaxation time describes the transfer of previously absorbed energy from spin to the surrounding environment, whereas the spin-spin relaxation time $T_{2}$ from spin to neighbouring spins. Values of $T_{1}$ reflect relative free water content in relation to bound water, while values of $T_{2}$ describe the dynamics of molecules in both, free and bound, water fractions. Distributed exponential analysis of the NMR $T_{2}$ relaxation data revealed the existence of distinctly different water populations. Values of $T_{21}$, the socalled short component, describe spin-spin relaxation of the bound water fraction, while values of $T_{22}$ concern spin-spin relaxation of the free water fraction $[18,19]$.

The purpose of the research described in this paper was to evaluate the influence of the addition of potato juice, both freshly squeezed and stabilized by spray-drying on the water binding capacity in poultry pate. The observed differences were analysed with respect to the alterations in water dynamics that occurred during processing. The physical method which has been applied to this study allows you to observe changes at the molecular level.

\section{Materials and methods}

\section{Meat}

Pates were prepared, according to the method described in Polish Patent Application [22], using meat from turkey shank (without skin), pork jowl, and pork liver. The raw materials used, as well as the recipe, were chosen complying with the dietetic recommendation addressed at patients suffering from inflammatory bowel disease by the Regional Branch of the Polish Association Supporting People with Inflammatory Bowel Disease.

\section{Potato juice}

Freshly squeezed juice from potato variety "Agatha" and spray-dried powder obtained from it were used for enrich of pate. Dried juice was obtained with a pilot scale P-dryer Niro Atomizer 6.3 (Denmark) using the following conditions: air temperature of $170{ }^{\circ} \mathrm{C}$ at the inlet to the drying chamber and $95^{\circ} \mathrm{C}$ at the outlet, and juice flow rate of $12 \mathrm{dm} / \mathrm{h}$. The dry mass of the powder was $90.0 \pm 0.5 \%$.

\section{Preparation of samples}

The meat used for preparation, excluding liver, was cooked at $70{ }^{\circ} \mathrm{C}$. Following cooking, a grinder equipped with a $3 \mathrm{~mm}$ mesh was used to grind the meat. Next, the meat was combined with the broth obtained during cooking and spices, and mixed in a bowl cutter at $55{ }^{\circ} \mathrm{C}$. Potato juice was added at this stage, substituting an adequate amount of broth. Homogenized raw liver was added to the mass and mixed with it until homogeneity was obtained. Samples of the forcemeat were collected at this stage. Finally, the mass was stuffed into $40 \mathrm{~mm}$ barrier stuffing tubes, and $150 \mathrm{~mm}$ long batons were formed and cooked at $90{ }^{\circ} \mathrm{C}$ until a temperature of $72{ }^{\circ} \mathrm{C}$ was achieved in the geometric center of the baton. Thus, prepared batons were cooled with cold water and stored in a refrigerator for further sampling. Table 1 presents the recipes used for the preparation of the test and reference samples.

The amount of potato juice used for enrichment by substitution of a part of the broth was calculated so as to obtain identical content of dry mass in the test and reference samples. Thermally untreated forcemeat and final pate, both without potato juice addition, served as respective references.

\section{Measurements of water activity}

The temperature changes of the equilibrium water activity $a_{\mathrm{w}}$ in the forcemeats were conducted using a water diffusion and activity analyzer ADA-7 (COBRABID, Poznań, 
Table 1 Recipes of the test and reference samples

\begin{tabular}{llll}
\hline Ingredient & $\begin{array}{l}\text { Reference } \\
(\mathrm{g} / 100 \mathrm{~g})\end{array}$ & $\begin{array}{l}\text { Pate with fresh } \\
\text { potato juice } \\
(\mathrm{g} / 100 \mathrm{~g})\end{array}$ & $\begin{array}{l}\text { Pate with } \\
\text { dried potato } \\
\text { juice }(\mathrm{g} / 100 \mathrm{~g})\end{array}$ \\
\hline Turkey shank meat & 42.85 & 42.85 & 42.56 \\
Pork jowl & 19.47 & 19.47 & 19.34 \\
Pork liver & 15.55 & 15.55 & 15.44 \\
Broth & 19.59 & 10.00 & 19.46 \\
Spice mix & 2.54 & 2.54 & 2.52 \\
Fresh potato juice & 0.00 & 9.59 & 0.00 \\
Dried potato juice & 0.00 & 0.00 & 0.68 \\
\hline
\end{tabular}

Poland) with automatic recording of water evacuation from individual samples. Detailed characteristics of the experimental method were specifically described by Stangierski et al. [23]. The measurements were performed at temperature in the range of $15-60{ }^{\circ} \mathrm{C}$. Once the measurement temperature was reached, it was controlled with $0.05^{\circ} \mathrm{C}$ accuracy. Calculations were performed using dedicated software by applying the non-linear least-square algorithm. Precision of the $\mathrm{a}_{\mathrm{w}}$ determination was determined by means of standard deviation.

The influence of temperature on the water activity was described using the following Arrhenius-type equation:

$a_{\mathrm{w}}=a_{\mathrm{w} 0} \exp \left(\frac{E_{\mathrm{A}}}{R T}\right)$,

where $E_{\mathrm{A}}$ is the activation energy of water transport in forcemeat, $R$ is the gas constant, $\mathrm{T}$ is the temperature in $K$, and $a_{\mathrm{w} 0}$ is a pre-exponential factor corresponding to the water activity at an infinite temperature.

Using Eq. (1), values of activation energy of water transport were calculated in forcemeats during thermal treatment.

\section{NMR measurements}

Forcemeat samples or pate samples of $0.2 \mathrm{~cm}^{3}$ were placed in measuring test tubes and sealed using Parafilm ${ }^{\circledR}$. Measurements of the spin-lattice $\left(T_{1}\right)$ and spin-spin $\left(T_{2}\right)$ relaxation times were performed using a pulse NMR spectrometer operating at $15 \mathrm{MHz}$ (Ellab-Poland). Forcemeats were measured at temperature in the range of $10-85^{\circ} \mathrm{C}$. The pates were measured at $(25.0 \pm 0.5){ }^{\circ} \mathrm{C}$.

The inversion-recovery $(\pi-t-\pi / 2)$ impulse sequence [24] was applied for measurements of $T_{1}$ relaxation times.

Distances between impulses $(t)$ were changed within the range from 3 to $1800 \mathrm{~ms}$ for the measurements at low temperatures (below $40{ }^{\circ} \mathrm{C}$ ) and from 6 to $2800 \mathrm{~ms}$ for the measurements at high temperatures (above $40{ }^{\circ} \mathrm{C}$ ). Repetition time was from 15 to $25 \mathrm{~s}$ for respective temperature ranges. Each time, 32 FID (free induction delay) signals and 110 points for each FID signal were collected.

Calculations of the spin-lattice relaxation time values were performed with the assistance of the CracSpin program [25], a program for calculating relaxation parameters from experimental data using "spin grouping" approach. Marquardt's method of minimization was applied for fitting multiexponential decays (from Eq. 2). Equation 2 describes non-linear growth of the magnitude of $M_{\mathrm{z}}(t)$ as a function of time $(t)$. This growth is determined by the time constant $T_{1}$. Precision of the relaxation parameters was determined using standard deviation. Time changes of the current value of the FID signal amplitude at the employed frequency of impulses were described by the following formula:

$M_{z}(t)=M_{0}\left(1-2 e^{\frac{-t}{T 1}}\right)$,

where: $M_{z}(t)$ is the actual magnetisation value, $M_{0}$ is the equilibrium magnetisation value, $t$ is the distance between impulses, and $T_{1}$ is a spin-lattice time relaxation time.

Measurements of the $T_{2}$ spin-spin relaxation times were taken using the pulse train of the Carr-Purcell-Meiboom-Gill spin echoes $\left(\pi / 2-\mathrm{TE} / 2-(\pi)_{n}\right)$ [24]. The distance between $\pi$ (TE) impulses was $3 \mathrm{~ms}$ (temperature values below $40{ }^{\circ} \mathrm{C}$ ) to $8 \mathrm{~ms}$ (temperature values below $40{ }^{\circ} \mathrm{C}$ ). Repetition time was 10-15 s for respective temperature ranges. The number of spin echoes $(n)$ amounted to 50 . Seven accumulation signals were employed.

To calculate the spin-spin relaxation time values, the authors applied the adjustment of values of the echo amplitudes to the formula $[18,21]$ :

$M_{x, y}(\mathrm{TE})=M_{0} \sum_{i=1}^{n} p_{i} e^{\frac{-\mathrm{TE}}{T_{2 i}}}$,

where $M_{x, y}$ (TE) is the echo amplitude; $M_{\mathrm{o}}$ is the equilibrium amplitude; TE is the distance between $\pi$ impulses; $p_{i}$ is the fraction of protons relaxing with the $T_{2 \mathrm{i}}$ spin-spin time.

Calculations were performed using dedicated software by applying the non-linear least-square algorithm. Precision of the relaxation parameters was determined using standard deviation.

The presence of two proton fractions was determined for all analysed systems.

All measurements were done in three repetitions. Oneway analysis of variance (ANOVA) was conducted independently for each dependent variable. Post hoc Tukey HSD multiple comparison test was used to identify statistically homogeneous subsets $\alpha=0.05$. Statistical analysis were done with Statistica 10 (StatSoft, Inc., 2011) software. 


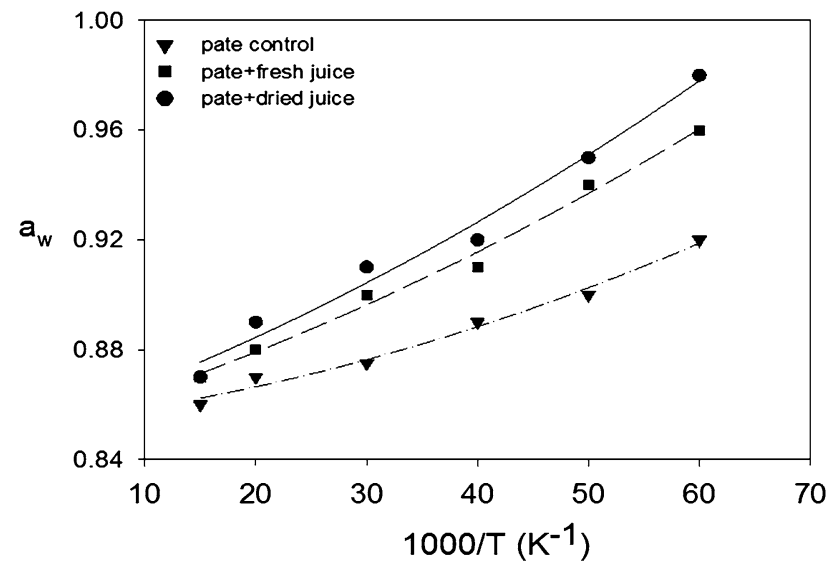

Fig. 1 Temperature changes of the water activity in analysed forcemeats

Table 2 Values of activation energy of water transport in forcemeats during thermal treatment

\begin{tabular}{ll}
\hline Sample & $E_{\mathrm{a}}(\mathrm{kJ} / \mathrm{mol})$ \\
\hline Reference forcemeat & $1.110 \pm 0.006$ \\
Forcemeat with fresh potato juice & $1.963 \pm 0.008$ \\
Forcemeat with dried potato juice & $1.696 \pm 0.003$ \\
\hline
\end{tabular}

\section{Results and discussion}

\section{Water activity and dynamics in the forcemeats during thermal treatment}

Water is a constituent of food which affects its safety, stability, quality, and physical properties. The state of water in food products may be described by a macroscopic parameter, the so-called water activity $\left(a_{\mathrm{w}}\right)$. Results of the conducted tests show increased equilibrium water activity in forcemeats containing potato juice (Fig. 1). Moreover, this effect was stronger for samples enriched with spray-dried juice than those with fresh juice.

Table 2 lists calculated values of activation energy of the process of water transport. The values indicate that the forcemeats containing potato juice are less susceptible to water evacuation than the reference forcemeat. The highest value of $E_{\mathrm{a}}$ was observed for the samples with fresh potato juice; thus, it is clear that no direct correlation exists between $E_{\mathrm{a}}$ and $a_{\mathrm{w}}$. Furthermore, the results show that it is not solely the fact of the addition of potato juice that influences the water holding mechanism, but also, that the form in which the juice is added plays a role. This in turn suggests that the constituents of potato juice undergo structural changes during thermal treatment associated with the process of spray-drying.

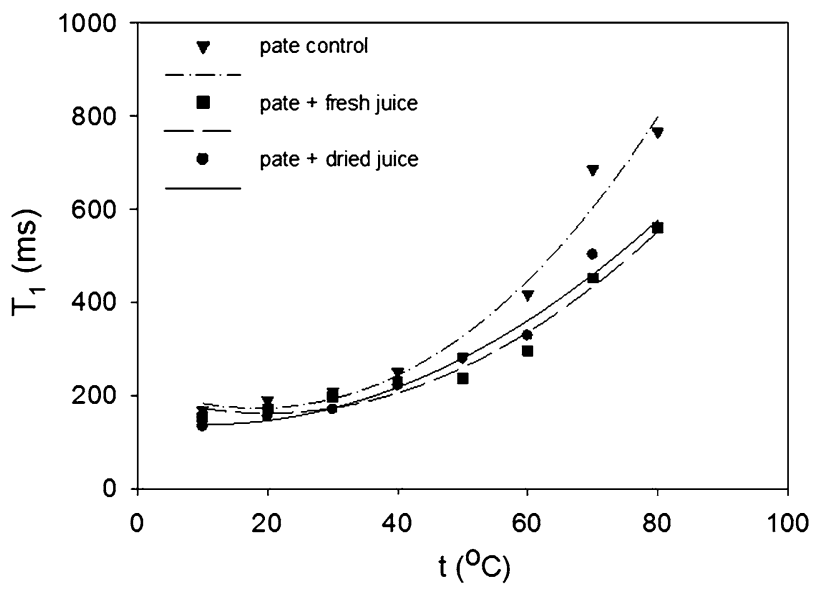

Fig. 2 Temperature changes of the spin-lattice relaxation times $T_{1}$ in analysed forcemeats

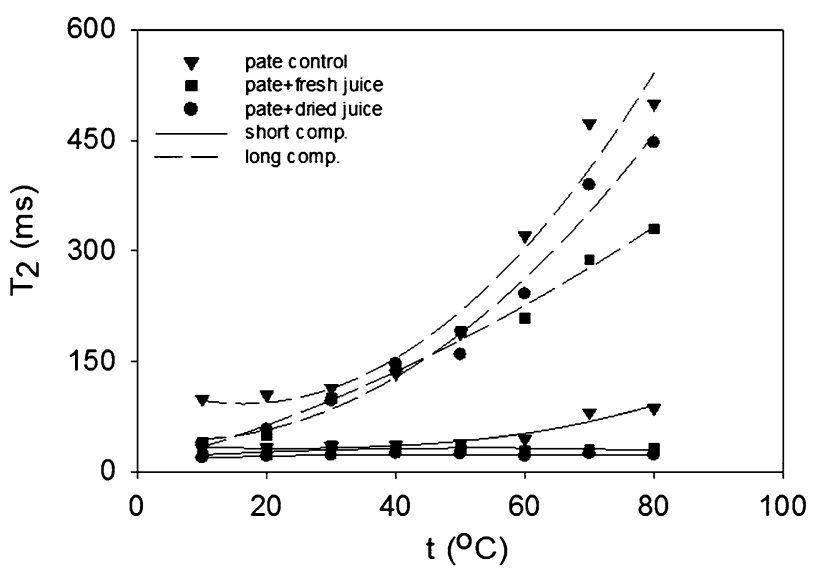

Fig. 3 Temperature changes of the spin-spin relaxation times $T_{2}$ in analysed forcemeats

The state of water in food products may also be described by molecular parameters measured with low-field NMR. It allows to analyse the ratio between bound and free water in a system, as well as the molecular dynamics of both these fractions. Figures 2 and 3 present the spin-lattice $\left(T_{1}\right)$ and spin-spin $\left(T_{2}\right)$ relaxation times in relation to temperature. Both parameters increase with increasing temperature. It is a typical phenomenon associated with enhanced mobility of protons of water molecules. No significant differences in $T_{1}$ values were noted at temperatures up to $40^{\circ} \mathrm{C}$. Above this temperature, the point at which all fat is liquefied and proteins denatured, pronounced differences were noticed between $T_{1}$ values obtained for the reference forcemeat and the forcemeats enriched with potato juice. The higher the $T_{1}$ value, the higher the ratio between free water and bound water. Thus, the addition of potato juice, in both tested forms, limited the amount of free water in the samples. 
The analysis of the spin-spin relaxation time $\left(T_{2}\right)$ revealed significant differences in molecular dynamics of both water fractions at temperatures exceeding $50{ }^{\circ} \mathrm{C}$. The short component $\left(T_{21}\right)$ of the spin-spin relaxation time was not influenced by temperature in the whole range of the test for potato juice-supplemented pates. Contrary to that, increasing $T_{21}$ values were observed for the reference forcemeat and test temperatures above $50{ }^{\circ} \mathrm{C}$. Partial protein unfolding is considered the main factor contributing to this effect [26]. In general, the mobility of free water is limited by the formation of ionic and hydrogen bonds between water molecules and macromolecules [27]. Thermal modifications in conformation of myofibrillar proteins influenced the intensity with which water was bound. This led to increased dynamics of water that manifested itself through higher values of short component $\left(T_{21}\right)$ of the spin-spin relaxation time. The effect was not observed in samples enriched with whichever of the tested forms of potato juice.

The long component of the spin-spin relaxation time $\left(T_{22}\right)$, one which describes the mobility of water molecules in the free water fraction, was observed to increase with increasing test temperature values. Throughout the whole temperature range, samples of the reference forcemeat showed the highest mobility of water molecules in the free water fraction. It should be pointed out, however, that water activity values (Fig. 1) were lower in the reference forcemeat than in the forcemeats supplemented with potato juice. Observed increase in water activity and decrease in the ratio of free water content to bound water content in forcemeats with potato juice (fresh and dried) in compare to forcemeat without potato juice mean that the active ingredients of the juice do not undergo a denaturing change. This may be suggestion to safety applied potato juice as component in poultry meat products.

\section{Molecular properties of water in pates}

During the final stage of pate production, thermal treatment is applied. The results of NMR analyses indicate that such treatment influences the absolute values of the spin-lattice relaxation time $T_{1}$ (Table 3). Furthermore, significant differences between values obtained for all the tested pates proved that both the sole fact of potato juice addition and its form

Table 3 Results of relaxation times of the tested pates

\begin{tabular}{llll}
\hline Sample & $T_{1}[\mathrm{~ms}]$ & $T_{21}[\mathrm{~ms}]$ & $T_{22}[\mathrm{~ms}]$ \\
\hline Reference pate & $215.8 \pm 1.8^{\mathrm{c}}$ & $25.1 \pm 1.6^{\mathrm{a}}$ & $58.7 \pm 9.6^{\mathrm{ab}}$ \\
Pate with fresh potato juice & $190.5 \pm 1.3^{\mathrm{b}}$ & $25.9 \pm 2.7^{\mathrm{a}}$ & $71.3 \pm 5.1^{\mathrm{b}}$ \\
Pate with dried potato juice & $163.4 \pm 0.9^{\mathrm{a}}$ & $25.6 \pm 2.1^{\mathrm{a}}$ & $53.9 \pm 1.2^{\mathrm{a}}$ \\
\hline
\end{tabular}

The means in the columns with different superscripts are significantly different $(P<0.05)$ used for enrichment affect the free/bound water ratio. Similar to forcemeats, the highest value of $T_{1}$ was obtained for the reference. Addition of potato juice resulted in a decrease of $T_{1}$. The pates containing spray-dried juice showed the lowest values of $T_{1}$ which indicated the strongest effect of limitation of the free water fraction in relation to bound water.

The obtained values of spin-spin relaxation time also display differences in water binding properties of the tested pates. The distributed exponential analysis of the NMR $T_{2}$ relaxation data revealed the existence of two distinctly different water populations characterized by short $\left(T_{21}\right)$ and long $\left(T_{22}\right)$ components. While there were no differences observed in the values of $T_{21}$, which indicates similar molecular dynamics of bound water among all the pates, the $T_{22}$ values suggest a significant alteration in the dynamics of the free water fraction. The lowest value of $T_{22}$ was obtained for samples of the pate that contained spray-dried potato juice. Thus, it can be stated that this pate not only contains the lowest amount of free water, but also this water fraction shows the most limited molecular dynamics. Limitation of molecular dynamics of water is commonly considered to be an effect of denaturation of myofibrillar proteins [28]. Such changes to protein conformation occur during thermal treatment of pates. Moreover, the process of spray-drying, carried out at $170{ }^{\circ} \mathrm{C}$, did presumably result in a significant denaturation of potato juice proteins. In contrast to this, the fresh juice, added directly to the forcemeat, underwent thermal treatment at a relatively low temperature of maximum $90{ }^{\circ} \mathrm{C}$. The differences in the $T_{22}$ values between the pates enriched with potato juice suggest that fresh potato juice contains proteins that significantly impact the dynamics of free water. Intense thermal exposition, and the consequent modification of protein structure, results in the loss of this feature.

Literature data suggest that changes at the molecular level that result in altered water dynamics impact the texture of the product [29]. Changes to textural properties of the pates corresponded with the changes observed among values of spin-lattice relaxation time that resulted from differences in the free/bound water ratio (Table 3).

\section{Conclusions}

It was found that dry potato juice bound water in low temperatures. However, following thermal treatment, the quantity of free water was found to increase, which led to amplified meat batter viscosity in comparison with the model system. A similar effect occurred when part of water was replaced by fresh potato juice. In such situation, it was probable that not only water but also potato juice itself was removed from the system. This was associated with the observed lack of 
interactions between juice and the remaining meat batter constituents at low temperatures.

Temperature changes of relaxation time values demonstrated that supplementation with potato juice limited quantities of free water and caused inhibition of the molecular dynamics of both water fractions. It is worth mentioning that the application of dried potato juice reduced quantities of free water in high temperatures. The performed analysis revealed that fresh potato juice contained in meat batters interacted only slightly with the remaining system constituents.

Introduction of potato juice to the recipe of pate has influence on the ratio between free and bound water fractions on every stage of production. The state in which water remains in the product is dependent not only on the sole fact of potato juice addition, but also on the form in which the juice is used.

Specifically, the differences include:

- Increased equilibrium water activity in forcemeat containing potato juice was noted. The effect was stronger when the pate was enriched with spray-dried juice.

- During thermal treatment of forcemeat containing potato juice, in both fresh and spray-dried forms, increased free water content and limitation of molecular dynamics of the bound water fraction were observed.

Acknowledgements This paper was financially supported by the Grant POIG 01.01.02-00-061/09 "Bioactive food" implemented within the Programme Innovative Economy 2007-2013.

\section{Compliance with ethical standards}

Conflict of interest The authors declare that they have no conflict of interest.

Compliance with ethics requirements This article does not contain any studies with human or animal subjects.

Open Access This article is distributed under the terms of the Creative Commons Attribution 4.0 International License (http://creativecommons.org/licenses/by/4.0/), which permits unrestricted use, distribution, and reproduction in any medium, provided you give appropriate credit to the original author(s) and the source, provide a link to the Creative Commons license, and indicate if changes were made.

\section{References}

1. Chrubasik S, Chrubasik C, Torda T, Madish A (2006) Efficacy and tolerability of potato juice in dyspeptic patients: a pilot study. Phytomedicine 13:11-15

2. Vlachojannis JE, Cameron M, Chrubasik S (2006) Medicinal use of potato-derived products. A systematic review. Phytother Res 24:159-162
3. Rale M-C, GueHguen J (2000) Fractionation of potato proteins: solubility, thermal coagulation and emulsifying properties. LWT Food Sci Technol. 33:380-387

4. Pouvreau L, Gruppen H, Piersma SR, van den Broek AM, van Koningsveld GA, Voragen AGJ (2001) Relative abundance and inhibitory distribution of protease inhibitors in potato juice from cv. Elkana. J Agric Food Chem 49:2864-2874

5. Ruseler-van Embden JGH, van Lieshout LMC, Laman JD (2004) Methods and means for preventing or treating inflammation or pruritis. US Patent. 6,723,354

6. Korpan YI, Nazarenko EA, Skryshevskaya IV, Martelet C, Jaffrezic-Renault N, El'skaya AV (2004) Potato glycoalkaloids: true safety or false sense of security? Trends Biotechnol 22:147-151

7. Burlingame B, Mouille B, Charrondiere R (2009) Nutrients, bioactive non-nutrients and anti-nutrients in potatoes. Critical Review. J Food Compos Anal. 2:494-502

8. Olejnik A, Białas W, Tomczyk J (2011) Lewandowicz G (2011) Cytotoxicity and genotoxicity of potato juice (in Polish: Cytotoksyczność i genotoksyczność soku z ziemniaka). Zeszyty Naukowe Uniwersytetu Ekonomicznego w Poznaniu. 205:118-125

9. Lewandowicz G, Kowalczewski P, Białas W, Olejnik A, Rychlik $\mathbf{J}$ (2012) Separation of the fractions of potato juice of different molecular weight and characterization of their biological activities (in Polish: Rozdział frakcji soku ziemniaczanego różniących się masą cząsteczkową i charakterystyka ich aktywności biologicznej). Biuletyn Instytutu Hodowli i Aklimatyzacji Roślin. 26:331-344

10. Lewandowicz G, Kowalczewski P, Olejnik A, Jodynis-Liebert J, Kujawska M, Lesiecki M (2012) The method for preparing of potato juice preparation and use thereof (in Polish: Sposób otrzymywania preparatu z soku ziemniaka oraz jego zastosowanie). Polish Patent Application No. P. 406918 2014)

11. Kowalczewski P, Celka K, Białas W, Lewandowicz G (2012) Antioxidant activity of potato juice. Acta Sci Polonorum Technologia Alimentaria. 11(2):175-181

12. Kowalczewski P, Sip A, Lewandowicz G (2014) Antimicrobial activity of potato juice (in Polish: Aktywność przeciwdrobnoustrojowa soku ziemniaczanego). Postępy Techniki Przetwórstwa Spożywczego. 2:56-61

13. Sun-Waterhouse D, Wadhwa SS (2013) Industry-relevant approaches for minimising the bitterness of bioactive compounds in functional foods: a review. Food Bioprocess Technol 6:607-627

14. Goetzke B, Nitzko S, Spiller A (2014) Consumption of organic and functional food. A matter of well-being and health? Appetite. 77:94-103

15. Jin SK, Park JH, Hur SJ (2014) Effect of substituting surimi with spent laying hen meat on the physicochemical characteristics of fried fish paste. Food Bioprocess Technol 7:901-908

16. Steen L, Fraeye I, De Mey E, Goemaere O, Paelinck H, Foubert I (2014) Effect of salt and liver/fat ratio on viscoelastic properties of liver paste and its intermediates. Food Bioprocess Technol 7:496-505

17. Sun-Waterhouse D, Waterhouse GIN (2015) Spray-drying of green or gold kiwifruit juice-milk mixtures; novel formulations and processes to retain natural fruit colourand antioxidants. Food Bioprocess Technol 8:191-207

18. Baranowska HM (2011) Water molecular properties in forcemeats and finely ground sausages containing plant fat. Food Biophys 6:133-137

19. Piatek M, Baranowska HM, Krzywdzinska-Bartkowiak M (2013) Microstructure and water molecular dynamics in meat after thawing. Fleischwirtschaft. 93(9):100-104

20. Stangierski J, Rezler R, Baranowska HM, Poliszko S (2013) Effect of enzymatic modification on frozen chicken surimi. Czech J Food Sci. 31:203-210 
21. Kowalczewski P, Lewandowicz G, Krzywdzińska-Bartkowiak M, Piątek M, Baranowska HM, Białas W, Jeziorna M, Kubiak $P$ (2015) Finely comminuted frankfurters fortified with potato juice—quality and structure. J Food Eng 167:183-188

22. Kowalczewski P, Lewandowicz G, Dolata W, Piotrowska E, Krzywdzińska-Bartkowiak M, Piątek M, Białas W (2012) Pate and a method for producing of pate. Polish Patent Application PL399064-A1

23. Stangierski J, Rezler R, Baranowska HM, Poliszko S (2012) Effect of enzymatic modification on chicken surimi. Czech J Food Sci. 30:404-411

24. Brosio E, Gianferri R (2009) In: Brosio E (ed) Basic NMR in foods characterization. Research Signpost, Kerala

25. Węglarz WP, Harańczyk H (2000) Two-dimensional analysis of the nuclear relaxation function in the time domain: the program CracSpin. J Phys D Appl Phys 33:1909-1920
26. Hughes JM, Oiseth SK, Purslow PP, Warner RD (2014) A structural approach to understanding the interactions between colour, water-holding capacity and tenderness. Meat Sci 98:520-532

27. Laage D, Stimemann G, Hynes JT (2010) Water reorientation in the hydration shells of hydrophilic and hydrophobic solutes. Sci China Phys Mech Astron 53:1068-1072

28. Mora B, Curti E, Vittadini E, Barbanti D (2011) Effect of different air/stream convention cooking methods on turkey breast meat: physical characterization, water status and sensory properties. Meat Sci 88:489-497

29. Li C, Wang D, Xu W, Gao F, Zhou G (2013) Effect of final cooked temperature on tenderness, protein solubility and microstructure of duck breast muscle. LWT Food Sci Technol 51:266-274 